\title{
Identification of cAMP-dependent kinase as a third in vivo ribosomal protein $\mathrm{S6}$ kinase in pancreatic $\beta$-cells
}

\author{
${ }^{\S}$ Claire E.J. Moore, ${ }^{\S}$ Jianling Xie, Edith Gomez and *Terence P. Herbert. \\ Department of Cell Physiology and Pharmacology, University of Leicester, Henry Welcome Building, \\ University Road, Leicester LE1 9HN, United Kingdom. \\ Running title: PKA; a third in vivo rpS6 kinase \\ §CEJM and JX contributed equally to this work

\begin{abstract}
*Address correspondence to: Dr. T. P. Herbert, The Department of Cell Physiology and University of Leicester, University Road, Leicester LE1 9HN, United Kingdom.
\end{abstract} \\ Pharmacology, Faculty of Medicine and Biological Sciences, The Henry Wellcome Building, \\ Tel: +44 (0)116 229 7148, Fax:+44 (0) 1162525045 e-mail: tph4@le.ac.uk
}

Key words: rpS6, PKA, GLP1, S6K, mTORC1, $\beta$-cell,

\begin{abstract}
Ribosomal protein S6 (rpS6) is phosphorylated in vivo by isoforms of p70 S6 kinase (S6K) and p90 ribosomal S6 kinase (Rsk) and there is good evidence that it plays a positive role in controlling pancreatic $\beta$-cell size and function. In this report, we demonstrate, in the pancreatic $\beta$-cell line MIN6 and islets of Langerhans, that agents which stimulate increases in cAMP, such as glucagon like peptide-1 (GLP1) or forskolin, lead to the phosphorylation of rpS6 exclusively at $\operatorname{Ser}(\mathbf{2 3 5} / 236)$ independently of the activation of the currently known in vivo rpS6 kinases via a pathway that is sensitive to inhibitors of cAMP-dependent kinase (PKA). This cAMP-dependent rpS6 kinase activity is also sensitive to PKI in vitro and PKA exclusively phosphorylates recombinant rpS6 on $\operatorname{Ser}(235 / 236)$ in vitro. Taken together, we conclude that PKA can phosphorylate rpS6 exclusively at $\operatorname{Ser}(235 / 236)$ in vivo in pancreatic $\beta$-cells, thus providing a potentially important link between cAMP signalling and the regulation of protein synthesis. Lastly, we provide evidence that PKA is also likely to phosphorylate $\operatorname{rpS6}$ on $\operatorname{Ser}(235 / 236)$ in vivo in a number of other mammalian cell types.
\end{abstract}

\section{Introduction}

The Eukaryotic 80S ribosome is a macromolecular complex composed of a small $40 \mathrm{~S}$ subunit, which decodes the mRNA, and a large 60S subunit, which is involved in peptidyl transfer. In higher eukaryotes, the 40S ribosomal subunit is made up of an 18S RNA and a total of 33 proteins, many of which are phosphorylated ${ }^{1 ; 2}$. However, of these phosphorylated proteins, ribosomal protein S6 (rpS6) has received the most attention as its phosphorylation is rapidly induced in response to nutritional, hormonal and mitogenic stimuli and it was the first identified substrate for p70S6K (S6K1) ${ }^{3}$.

rpS6 is phosphorylated by S6K at the C-terminus on Ser236, Ser235, Ser240, Ser244 and Ser247 in vitro ${ }^{4}$, which correspond to sites phosphorylated in vivo ${ }^{5}$. Deletion of the S6K (dS6K) gene in Drosophilia is embryonic lethal; however, a few flies survive and these have reduced body mass as a result of a smaller cell size rather than cell number ${ }^{6}$. Mammalian cells express two isoforms of S6K, S6K1 and S6K2, each encoded by a separate gene ${ }^{7}$ and in mice, deletion of the S6K1 gene (S6K $1^{-1-}$ ) is not lethal but the mice are significantly smaller than their wild type counterparts due to decreased cell size rather than decreased cell number ${ }^{78}$. In contrast, mice in which the S6K2 gene is deleted $\left(\mathrm{S}_{\mathrm{K} 2}{ }^{--}\right)$show a normal body and cell size compared to wild type littermates ${ }^{9}$. Mice in which both S6K1 and S6K2 $\left(\mathrm{S} 6 \mathrm{~K}^{-1-} / 2^{-1-}\right)$ were deleted have a similar phenotype to that of S6K ${ }^{-1-}$ mice but show a significant decrease in viability compared to the $\mathrm{S}_{6 \mathrm{~K}} 1^{-1-}$ mice ${ }^{9}$. Importantly, especially in relation to 
this study, the phosphorylation of rpS6 appears to play a particularly significant role in controlling pancreatic $\beta$-cell size and function as $\mathrm{S} 6 \mathrm{~K}^{-1-}$ mice and knock-in mouse in which all five phosphorylatable serine residues within $\mathrm{rpS6}$ are substituted to alanines $\left(\mathrm{rpS6}^{\mathrm{P}-1}\right)$ have comparatively smaller pancreatic $\beta$-cells, which co-insides with diminished levels of pancreatic insulin, hypoinsulinemia and impaired glucose tolerance ${ }^{8} 10$.

S6K2 is the predominant S6 kinase as growth factor induced phosphorylation of rpS6 at Ser(235/236) is reduced and phosphorylation at $\operatorname{Ser}(240 / 244)$ is undetectable in hepatocytes derived from S6K2 ${ }^{-/}$ knock-out mice ${ }^{9}$. In $\mathrm{S} 6 \mathrm{~K} 1^{-1 /} / 2^{-/-}$knock-out mice, a proportion of rpS6 remains phosphorylated on Ser(235/236), revealing the presence of another in vivo rpS6 Kinase ${ }^{9}$. This was identified as p90 ribosomal S6 kinase (Rsk) ${ }^{9}{ }^{11}$, a kinase that had previously been named due to its ability to readily phosphorylate rpS6 in vitro ${ }^{12}$.

Although extensively studied, the molecular mechanism by which rpS6 phosphorylation exerts its effects has proved enigmatic. It was originally thought to stimulate the recruitment of $5^{\prime} \mathrm{TOP}\left(5^{\prime}\right.$ terminal oligopyrimidine tract) mRNAs onto polysomes ${ }^{13}$. However, the translation of 5 'TOP mRNAs is unaffected in hepatocytes from both S6K $1^{-1-} / 2^{-/-}$knock-out mice ${ }^{9}$ and $\mathrm{rpS}^{\mathrm{P}-{ }^{-/}}$mice ${ }^{10}$. A recent study provided evidence that site specific phosphorylation of rpS6 on Ser(235/236) via Rsk promotes cap-dependent translation by facilitating the formation of pre-initiation translation complexes ${ }^{11}$.

The Glucagon like peptide-1 receptor (GLP1R) is a member of the G-protein coupled receptor (GPCR) super-family, which can couple to $G_{s} \alpha$ containing heterotrimeric $G$ proteins leading to the activation of adenylyl cyclase and the subsequent increase in the production of cAMP ${ }^{14}$. The GLP1R is highly expressed in pancreatic $\beta$-cells and is activated by the hormone GLP1, where it poteniates glucose stimulated insulin secretion, increases $\beta$-cell mass and improves $\beta$-cell function. These properties have made GLP1 the subject of intensive investigation as a potential treatment for type-2 diabetes. Interestingly, GLP1R activation potently stimulates S6K ${ }^{15}$. Therefore, GLP1 may promote increases in $\beta$-cell mass, at least in part, through increases in the phosphorylation status of rpS6. For this reason, we set out to investigate the signalling mechanism by which GLP1 stimulates rpS6 phosphorylation in pancreatic $\beta$-cells. In the process, we identified PKA as a third in vivo ribosomal kinase which specifically phosphorylates rpS6 on Ser(235/236) in $\beta$-cells and in a number of other cell types tested.

\section{Results}

Inhibition of phosphoinositide 3-kinase reveals that GLP1 and forskolin can stimulate the phosphorylation of rpS6 on Ser(235/236) via a S6K independent mechanism. In order to investigate the role of phosphoinositide 3-kinase (PI3K) in GLP1 stimulated phosphorylation of rpS6 in pancreatic $\beta$-cells, MIN6 cells, a pancreatic clonal $\beta$-cell line ${ }^{16}$, were incubated with glucose, GLP1 or forskolin (an activator of adenylyl cyclase) in the presence or absence of the PI3K inhibitors LY294002 or wortmannin. Glucose, GLP1 and forskolin led to a significant increase in the phosphorylation of $\mathrm{S} 6 \mathrm{~K}$, as determined by a shift in its mobility, the phosphorylation of rpS6 on Ser(235/236) and Ser(240/244) and the phosphorylation of PKB on Ser473 (figure 1a-c). Both LY294002 and wortmannin blocked glucose, GLP1 or forskolin stimulated phosphorylation of PKB, S6K1 and rpS6 on Ser(240/244). Glucose stimulated phosphorylation of rpS6 on Ser(235/236) was also blocked by LY294002 or wortmannin (figure 1a). Surprisingly, however, GLP1 and forskolin stimulated phosphorylation of rpS6 on Ser(235/236) was unaffected by the PI3K inhibitors (figures $1 \mathrm{~b}$ and c). To confirm that GLP1 stimulated phosphorylation of $\mathrm{rpS} 6$ at $\operatorname{Ser}(235 / 236)$ was indeed independent of both S6K1 and 2, we determined the activity of S6K1 and 2 in response to GLP1 in the presence and absence of LY294002. GLP1 led to an increase in both S6K1 and 2 activity, which was effectively inhibited by LY294002 (figure 1d and e). Taken together, these results provide evidence that GLP1 and forskolin, agents which elevate cAMP, can stimulate the phosphorylation of rpS6 on $\operatorname{Ser}(235 / 236)$ and $\operatorname{Ser}(240 / 244)$ by two distinct signalling pathways; where the phosphorylation of rpS6 at Ser(240/244) is dependent upon PI3K, likely mediated via the activation of 
PKB and S6K, whereas the phosphorylation of rpS6 on Ser(235/236) is mediated independently of PI3K, PKB and S6K1 and 2.

mTORC1 dependent site-specific dephosphorylation of rpS6 on Ser(235/236). To determine whether GLP1 and forskolin stimulated phosphorylation of rpS6 on Ser(235/236) is dependent upon the activation of mTORC1, MIN6 cells were incubated with glucose, glucose plus GLP1 or forskolin in the absence or presence of rapamycin, a specific inhibitor of mTORC1 (figure 2a). Rapamycin blocked glucose stimulated phosphorylation of rpS6 at Ser(240/244) and Ser(235/236), which paralleled the inhibition of S6K1. Rapamycin also blocked GLP1 and forskolin stimulated phosphorylation of rpS6 at Ser(240/244), which again paralleled a decrease in S6K1 phosphorylation and significantly reduced/blocked forskolin and GLP1 stimulated phosphorylation of rpS6 at Ser(235/236). These results indicate that GLP1 and forskolin stimulated rpS6 phosphorylation at Ser(235/236) is dependent upon mTORC1 activity but independent of S6K1 and 2, the only known rpS6 kinases which lies downstream of mTORC1. As anticipated, the phosphorylation of PKB at Ser473 in response to glucose, GLP1 and forskolin was unaffected by rapamycin (figure 2a).

It has been reported that $\mathrm{m}(\mathrm{TOR})$ inhibition by nutrient withdrawal or rapamycin can result in the activation of protein phosphatase $2 \mathrm{~A}$ (PP2A) ${ }^{17}$. Therefore, the rapamycin sensitivity of GLP1 and forskolin stimulated phosphorylation of $\mathrm{rpS} 6$ on $\operatorname{Ser}(235 / 236)$ could be attributed to the activation of PP2A. To investigate this possibility, we determined the effect of okadaic acid (a selective inhibitor of protein phosphatases 1 and 2A) and cantharidin (a selective inhibitor of PP2A) (figure 2b) on rapamycin induced inhibition of GLP1 stimulated rpS6 phosphorylation on Ser(235/236). As expected, rapamycin inhibited GLP1 induced rpS6 phosphorylation on Ser(240/244) and $\operatorname{Ser}(235 / 236)$. However, okadaic acid and cantharidin, in the presence of rapamycin, dose dependently stimulated the restoration of GLP1 stimulated rpS6 phosphorylation on Ser(235/236), yet had no effect on the phosphorylation of rpS6 on Ser(240/244) (figures 2b). Collectively, these results provide evidence that inhibition of mTORC1 by rapamycin results in the activation of a phosphatase that could be PP2A, which specifically dephosphorylates rpS6 on Ser(235/236). Therefore, GLP1 stimulated rpS6 phosphorylation on Ser(235/236) is likely to be independent of mTORC1 activation or the activation of its downstream effectors.

Rsk is not responsible for GLP1 stimulated site-specific phosphorylation of rpS6 on Ser(235/236). p90 ribosomal S6 kinase (Rsk) is directly phosphorylated and activated by Erk and can specifically phosphorylate rpS6 on Ser(235/236) via an mTORC1 independent pathway in response to growth factor stimulation ${ }^{9 ; 11}$. To determine whether GLP1 stimulated site specific phosphorylation of rpS6 on Ser(235/236) is mediated by Rsk, MIN6 cells were incubated with glucose or glucose plus GLP1 in the absence or presence of the MEK inhibitor PD-184352 and its effect on GLP1 stimulated rpS6 phosphorylation assessed (figure 3a). Additionally, in order to investigate selectively the phosphorylation of rpS6 on Ser(235/236), cells were also incubated in the presence and absence of the PI3K inhibitor LY294002 to block signalling through S6K (figure 3a). As observed previously (see figure 1), LY294002 blocked GLP1 stimulated rpS6 phosphorylation on Ser(240/244) and had no significant effect on the phosphorylation of rpS6 on Ser(235/236). LY294002 treatment also stimulated Erk phosphorylation which was effectively inhibited by PD-184352. This LY294002 stimulated Erk activity maybe mediated by LY294002's ability to block $\mathrm{K}_{\mathrm{v}}$ currents in pancreatic $\beta$ cells ${ }^{18}$, which in turn may stimulate $\mathrm{Ca}^{2+}$ influx through L-type VGCC, which is sufficient to stimulate Erk activation in $\beta$-cells ${ }^{19}$. GLP1 stimulated rpS6 phosphorylation at Ser(235/236) was unaffected by PD-184352 either in the presence or absence of LY294002. Unexpectedly, PD-184352 blocked glucose stimulated rpS6 phosphorylation on $\operatorname{Ser}(235 / 236)$ and $\operatorname{Ser}(240 / 244)$. However, we found that PD-184352 activated AMPK, as determined by its increased phosphorylation on Thr172 and phosphorylation of a downstream effector acetyl co-carboxylase on Ser79. Increased AMPK activity has been reported to inhibit glucose stimulated mTORC1 signalling and the activation of S6K in $\beta$-cells ${ }^{20}$. Indeed, PD-184352, possibly via the activation of AMPK, inhibited mTORC1 as assessed by the phosphorylation status of two downstream targets of mTORC1, 4EBP1 on Ser65 and S6K. Therefore, inhibition of glucose stimulated rpS6 phosphorylation by PD-184352 may be mediated by the activation of AMPK and the inhibition of mTORC1. We also observed that other MEK inhibitors, U0126 and PD-98059, also activated AMPK in MIN6 cells (unpublished results 
(Moore and Herbert)). Indeed, it has been previously been reported that both PD98059 and U0126 activate AMPK in HELA and HEK293 cells ${ }^{21}$. Importantly, PD-184352, at a concentration which effectively inhibited GLP1 stimulated Erk phosphorylation, had no observable effect on GLP1 stimulated phosphorylation of rpS6 on Ser235/236. Given that these MEK inhibitors also activate AMPK, which clearly complicates the interpretation of these experiments, we used an alternative approach to inhibit the Erk signalling cascade and hence Rsk. MIN6 cells were infected with recombinant adenovirus encoding Mitogen-activated protein kinase phosphatase 3 (AdMPK3), a dualspecific phosphatase that dephosphorylates the activation loop of ERK1/2 with very high specificity ${ }^{22}$, and its effect on GLP1 stimulated rpS6 phosphorylation was assessed (figure 3b). The phorbol ester TPA, which potently activates Erk and Rsk, was used a positive control (figure 3b). Overexpression of MKP3 effectively blocked TPA induced Erk phosphorylation and the phosphorylation of Rsk as assessed by a decrease in Rsk mobility on a SDS-polyacrylamide gel. Yet, overexpression of MKP3 had no effect on GLP1 stimulated rpS6 phosphorylation on either Ser(235/236) or $\operatorname{Ser}(240 / 244)$ in either the presence or absence of LY294002 (figure 3b). Moreover, over expression of MKP3 had no effect on glucose stimulated rpS6 phosphorylation on either Ser(235/236) or Ser(240/244) indicating that the effects of PD-184352 on glucose stimulated phosphorylation of rpS6 observed in figure $3 a$ were likely to be mediated by the activation of AMPK.

Taken together, these results provide strong evidence that Rsk is not responsible for site specific phosphorylation of rpS6 on Ser(235/236) by GLP1 in pancreatic $\beta$-cells.

Novel/classical isoforms of PKC are not responsible for GLPI stimulated site-specific phosphorylation of rpS6 on Ser(235/236). Given that the phosphorylation of rpS6 on Ser(235/236) in response to GLP1 is independent of the known in vivo rpS6 kinases, S6K and Rsk, we sought to identify possible candidate kinases that could phosphorylate rpS6 on Ser(235/236) using a program which recognises conserved kinase recognition motifs within proteins (group-based phosphorylation site predicting and scoring platform) ${ }^{23}$. Several kinases that could potentially phosphorylate rpS6 at Ser(235/236) were identified. These included the known S6 kinases S6K and Rsk, as well as PKB, PKC and cAMP-dependent kinase (PKA). However, we have already ruled out the possibility that S6K or Rsk is responsible for GLP1 stimulated rpS6 phosphorylation on Ser(235/236). PKB was also ruled out as GLP1 stimulated phosphorylation of PKB on Ser473 is completely blocked by LY294002 yet the phosphorylation of $\mathrm{rpS6}$ on $\operatorname{Ser}(235 / 236)$ is unaffected (figure 1). To investigate whether PKC is responsible for GLP1 stimulated rpS6 phosphorylation on Ser(235/236), MIN6 cells were treated with GLP1 in the presence or absence of BIM, Ro320432 or Gö6976, selective inhibitors of the novel/classical isoforms of PKC (PKCn/c) (figure 4). GLP1 was also added to MIN6 cells chronically pre-stimulated with TPA to down-regulate both $\mathrm{PKCn} / \mathrm{c}$ isoforms (figure 4). To selectively investigate the phosphorylation of rpS6 on $\operatorname{Ser}(235 / 236)$, cells were also incubated in the presence and absence of the PI3K inhibitor LY294002 to block signalling through S6K. TPA, which acts via the activation of both $\mathrm{PKCn} / \mathrm{c}$, was used as a positive control. As anticipated, chronic pre-stimulation of cells with TPA or addition of BIM, Ro320432 and Gö6976 blocked TPA induced phosphorylation of Erk1/2 and rpS6 yet had no effect on GLP1 stimulated rpS6 phosphorylation on Ser(235/236) either in the presence or absence of LY294002. As shown previously (figure 1), LY294002 effectively blocked GLP1 signalling to rpS6 on Ser(240/244). These results demonstrate that neither classical or novel isoforms of PKC are responsible for GLP1 stimulated rpS6 phosphorylation on Ser(235/236).

cAMP-dependent kinase (PKA) selectively phosphorylates rpS6 on Ser(235/236) in vitro. Having ruled out the possibility that S6K, Rsk, PKC and PKB are responsible for GLP1 stimulated rpS6 phosphorylation on Ser(235/236) (figures 1, 3 and 4), we investigated whether PKA was responsible for GLP1 stimulated selective phosphorylation of rpS6 on Ser(235/236). Indeed, PKA appeared a likely candidate as PKA is activated by agents that elevate cAMP, such as GLP1 and forskolin, and PKA was predicted to selectively phosphorylate $\mathrm{rpS6}$ on $\operatorname{Ser}(235 / 236)$ in silico. Initially, we investigated whether the recombinant catalytic subunit of PKA (PKAc), or a control active S6K1, could directly phosphorylate rpS6 specifically on Ser(235/236) in an in vitro kinase assay using a GST fusion protein containing the C-terminus of rat rpS6 as substrate (GST-S6). PKAc readily stimulated the incorporation of ${ }^{32} \mathrm{P}$ into GST-S6 but not into a mutant rpS6 protein in which Ser(235) 
and $\operatorname{Ser}(236)$ were replaced by alanines (GST-S6AA), indicating that PKA exclusively phosphorylates rpS6 on Ser(235/236) (figure 5ai and iii). The stoichiometry of PKA-induced phosphorylation of GST-S6 in vitro was determined to be $1.74 \mathrm{~mol} / \mathrm{mol}$. In contrast, S6K could phosphorylate GST-S6 and GST-S6AA (figure 5ai). It has been reported that the phosphorylation of rpS6 on Ser(235/236) precedes the phosphorylation of $\operatorname{Ser}(240 / 244){ }^{24}$. Therefore, the phosphorylation of $\mathrm{rpS} 6$ on $\operatorname{Ser}(235 / 236)$ may be required for its subsequent phosphorylation on $\operatorname{Ser}(240 / 244)$. In order to rule out this possibility, we also investigated if PKAc could stimulate the incorporation of ${ }^{32} \mathrm{P}$ into a mutant of rpS6 where Ser(235/236) were replaced with phospho-mimetic aspartic acid residues (GST-S6DD). However, neither PKAc or S6K1 was able to phosphorylate GST-S6DD (unpublished results) indicating that perhaps the aspartic acids were unable to act as a true phosphomimetic. Therefore, we also looked at the phosphorylation of GST-S6 in vitro by PKAc or S6K1 using phospho-specific antibodies. Phosphorylation of GST-S6 by PKAc was readily detectable at Ser(235/236) but not at Ser(240/244) (figure 5b). Therefore, PKA selectively phosphorylate rpS6 on Ser(235/236) in vitro. In contrast, S6K1 phosphorylation of GST-S6 was detectable at both Ser(235/236) and Ser(240/244). These results are in agreement with a previous report in which the sites of PKA phosphorylation of rpS6 in vitro, using purified ribosomes from rats as substrate, were mapped to Ser235 and Ser236 ${ }^{25}$.

Evidence that PKA phosphorylates rpS6 on Ser(235/236) in vivo. Agents that lead to an increase in cAMP also lead to the site specific phosphorylation of rpS6 on Ser(235/236) via a S6K, Rsk and $\mathrm{PKCn} / \mathrm{c}$ independent mechanism. Additionally, we show that PKA, which is activated by elevated levels of cAMP, effectively and selectively phosphoylates $\mathrm{rpS6}$ on $\operatorname{Ser}(235 / 236)$ in vitro. To determine whether GLP1 and forskolin treatment resulted in the activation of an in vitro rpS6 kinase activity, rpS6 kinase activity was assayed, using either recombinant GST-S6 or GST-S6AA as substrates, in lysates from MIN6 cells treated with GLP1 or forskolin in either the absence or presence of LY294002 and PD-184352 to inhibit both S6K and Rsk activity (figure 6a). Both GLP1 and forskolin treatment led to an increase in S6 kinase activity compared to control lysates as determined by increased ${ }^{32} \mathrm{P}$-incorporation into GST-S6. This activity was also undiminished in lysates from cells treated by LY294002 and PD-184352. However, the addition of the PKA inhibitor PKI effectively blocked this in vitro rpS6 kinase activity, demonstrating that PKA is the major in vitro S6 kinase found in cell lysates treated with either GLP1 or forskolin. Moreover, GLP1 or forskolin was unable to stimulate the incorporation of ${ }^{32} \mathrm{P}$ into GST-S6AA, demonstrating that this S6 kinase activity is directed solely towards $\operatorname{Ser}(235 / 236)$.

To provide further evidence that PKA is an in vivo rpS6 kinase MIN6 cells were treated with GLP1 or forskolin in the presence or absence of the cell permeable selective adenylyl cyclase inhibitor MDL12,330A and PKA inhibitor H89 (figure 6b and c). Both MDL12,330A and H89 inhibited GLP1 and forskolin stimulated rpS6 phosphorylation. In addition, cells were treated with a penetratin linked cell permeable PKI peptide $\left(\mathrm{PKI}_{\mathrm{RR}}\right)$ that specifically inhibits PKA or, as a negative control, a penetratin linked PKI peptide in which 2 arginine residues, critical for binding of PKI to PKA ${ }^{26}$, were replaced by alanines $\left(\mathrm{PKI}_{\mathrm{AA}}\right.$ ) (figure $6 \mathrm{~d}$ ). $\mathrm{PKI}_{\mathrm{RR}}$ but not $\mathrm{PKI}_{\mathrm{AA}}$ effectively inhibited forskolin stimulated rpS6 phosphorylation. $\mathrm{PKI}_{\mathrm{RR}}$ but not $\mathrm{PKA}_{\mathrm{AA}}$ also inhibited GLP1 stimulated phosphorylation of rpS6 on Ser(235/236) in the absence or presence of the PI3K inhibitor LY29002. This data, along with the results presented in figures 1 to 5 , provide strong evidence that PKA acts as an in vivo rpS6 kinase.

Evidence that PKA phosphorylates rpS6 on Ser(235/236) in islets of Langerhans. In order to provide evidence that PKA is able to phosphorylate rpS6 in primary $\beta$-cells, rat islets of Langerhans were incubated with glucose, glucose plus GLP1 or forskolin in the presence or absence of the PI3K inhibitors LY294002 or wortmannin (figure 7a), the MEK inhibitor PD-184352 (figure 7b) or the mTORC1 inhibitor rapamycin (figure 7c). Glucose, glucose plus GLP1 and forskolin all led to increases in the phosphorylation of rpS6 (figure 7). Glucose and glucose plus GLP1 also led to increases in PKB phosphorylation (figure 7a). Glucose stimulated phosphorylation of rpS6 and PKB was inhibited by LY294002 and wortmannin (figure 7a). GLP1 and forskolin stimulated 
phosphorylation of rpS6 on $\operatorname{Ser}(240 / 244)$ was also blocked by LY294002 and wortmannin as was GLP1 stimulated PKB phosphorylation (figure 7a). However, GLP1 and forskolin stimulated phosphorylation of rpS6 on Ser(235/236) was resistant to both LY294002 and wortmannin indicating that cAMP-dependent phosphorylation of $\mathrm{rpS6}$ on Ser(235/236) is independent of S6K in islets (figure 7a). GLP1 stimulated phosphorylation of rpS6 on Ser(235/236) was also resistant to PD-184352 at a concentration that effectively inhibited TPA induced phosphorylation of Erk, indicating that phosphorylation of this site is also independent of Rsk in islets (figure 7b). To provide evidence that PKA is an in vivo rpS6 kinase in islets, islets were treated with GLP1 in the presence or absence of the selective PKA inhibitor H89 (figure 7c). H89 inhibited GLP1 stimulated rpS6 phosphorylation on Ser(235/236) and Ser(240/244). H89 had no effect on the phosphorylation of S6K1 on Thr389. Taken together, these results provide evidence that Ser(235/236) is being phosphorylated by a PKA dependent mechanism. Similar to the results obtained in MIN6 cells. Rapamycin treatment inhibited glucose, GLP1 or forskolin stimulated rpS6 phosphorylation on all sites investigated (figure 7d) , presumably through the activation of a phosphatase (see figure 2). These results provide evidence that the phosphorylation of rpS6 in islets by agents which elevate cAMP occurs via a similar, if not identical, mechanism to that observed in MIN6 cells.

Evidence that PKA phosphorylates rpS6 on Ser(235/236) in other cell types. In order to investigate whether PKA is also able to phosphorylate rpS6 on Ser(235/236) in other cell types, the human fibroblast cell line NIH3T3, the rat pheochromocytoma cell line PC12, the human neuroblastoma cell line SY-SH5Y, the human embryonic kidney cell line HEK293 and the Chinese Hamster Ovarian (CHO) cell line, and as control MIN6 cells, were treated with Forskolin and IBMX to elevate cAMP in the absence or presence of H89, LY294002, LY294002 plus PD184352, or rapamycin (figure 8). In all cell types tested Forskolin and IBMX stimulated the phosphorylation of rpS6 on Ser(235/236) and this was blocked by H89. Importantly, the phosphorylation of rpS6 on Ser(235/236) was resistant to LY294002 or LY294002 plus PD184352 in MIN6 and HEK293 cells and partially resistant in PC12, SY-SH5Y, and NIH3T3 cells. In addition, in HEK293, PC12, SYSH5Y, and NIH3T3 cells the phosphorylation of $\operatorname{rpS6}$ at Ser(235/236) phosphorylation was also resistant to rapamycin. This demonstrates that, in MIN6, HEK293, PC12, SY-SH5Y, and NIH3T3, increases in cAMP can stimulate the phosphorylation of rpS6 on Ser(235/236) via a Rsk and S6K independent mechanism, which is sensitive to H89. Therefore, based on these results and the results presented throughout the paper, rpS6 can be phosphorylated on Ser(235/236) by PKA in a number of different cell types. The phosphorylation of rpS6 on Ser(240/244) was blocked by LY294002, indicating that the phosphorylation of this site is dependent on PI3K and possibly mediated by S6K. In CHO cells the phosphorylation of rpS6 on Ser(235/236) was also blocked by LY294002 indicating that in this cell type cAMP induced phosphorylation of rpS6 is likely mediated by S6K. .

\section{Discussion}

rpS6 was shown to be phosphorylated at multiple sites in response to partially hepatoctomy in rats, a treatment which leads to the rapid increase in protein synthesis ${ }^{27}$. The sites phosphorylated on rpS6 in vivo were mapped to the C-terminus and identified as Ser235, Ser236, Ser240, Ser244 and Ser247 5; 28; 29. Although a number of protein kinases were shown to phosphorylate rpS6 in vitro, including protease-activated kinases, PKC and PKA, these were unable to phosphorylate rpS6 at all the sites identified in vivo and their activation in vivo did not precede increases in rpS6 phosphorylation (reviewed by ${ }^{1 ; 30}$ ). However, a predominant mitogen activated S6 kinase activity, which could phosphorylate rpS6 on all 5 sites identified in vivo, and whose activity preceeded the phosphorylation of rpS6 in vivo, was isolated and named p70S6 kinase (S6K1) ${ }^{40}$. In addition, inhibition of mTORC1, an upstream activator of S6K1/2, inhibited the phosphorylation of rpS6 in vivo ${ }^{7 ; 31 ; 32}$. Therefore, $\mathrm{S} 6 \mathrm{~K}(1 / 2)$ was considered to be the only authentic in vivo rpS6 kinase. Examination of the phosphorylation status of $\mathrm{rpS} 6$ in hepatocytes from $\mathrm{S} 6 \mathrm{~K} 1 / 2^{-/}$mice demonstrated that $\mathrm{S} 6 \mathrm{~K}$ is the predominant rpS6 kinase but also revealed the presence of another in vivo kinase which: 1.) could exclusively only phosphorylate rpS6 on Ser(235/236); 2.) was sensitive to inhibitors of MEK; and 3.) was insensitive to rapamycin ${ }^{9}$. This kinase was identified as Rsk, a serine/threonine kinase that is 
activated in response to mitogens such as EGF and Serum ${ }^{11}$. However, the possibility remained that other in vivo rpS6 kinases existed as rpS6 phosphorylation had only been studied in response to a limited number of mitogens, none of which stimulate increases in cAMP, in hepatocytes derived from S6K $1 / 2^{-1-}$ mice and S6K $1 / 2^{-1-}$ MEFs ${ }^{9}$. In this study, we identify PKA as a third in vivo rpS6 kinase and show that this kinase exclusively phosphorylates rpS6 on Ser(235/236). Interestingly, there are numerous reports demonstrating that agents which elevate cAMP lead to an increase in the phosphorylation of rpS6. However, increased cAMP can activate PKB ${ }^{33 ; 34 ; 35 ; 36}$, which in turn can stimulate $\mathrm{S} 6 \mathrm{~K} 1 / 2$ via the inactivation of Tsc1/2 and the subsequent increase in mTORC1 activity ${ }^{37}$. In addition, increases in cAMP can also activate the Erk signalling pathway ${ }^{38}$, which can, via Rsk, directly phosphorylate rpS6 ${ }^{11}$. Moreover, the Erk signalling pathway can stimulate the activity of S6K1/2 via the inactivation of the Tsc1/2 and the subsequent activation of mTORC1 ${ }^{39 ; 40 ; 41 .}$ Therefore, prior to this report, cAMP-dependent phosphorylation of $\mathrm{rpS6}$ was likely assumed to be mediated by an increase in the activation of Rsk and/or S6K. Indeed, in all the cell types we tested, cAMP-dependent increases in the phosphorylation of rpS6 at Ser(240/244) were blocked by the PI3K inhibitor LY294002, indicating that phosphorylation at these sites is likely mediated by S6K; however, in most cases, cAMP stimulated increases in the phosphorylation of rpS6 on Ser(235/236) was resistant to inhibitors of PI3K or MEK but sensitive to H89.Therefore, we believe that cAMPdependent phosphorylation of rpS6 on Ser(235/236) in pancreatic $\beta$-cells, as well as in many other cell types, is mediated by PKA in vivo.

Agents which stimulate increases in cAMP can either inhibit or stimulate protein synthesis depending upon physiological stimuli and cell type. In $\beta$-cells, the GLP1R agonist exendin- 4 stimulates protein synthesis via a cAMP-dependent mechanism ${ }^{42}$. This is possibly facilitated by PKA-dependent phosphorylation of rpS6, as site specific phosphorylation at Ser(235/236) has previously been shown to stimulate preinitiation translation complex assembly and the initiation of cap-dependent translation 11. However, polysomes from livers of $\mathrm{rpS6}^{\mathrm{p}-/}$ mice are similar to those found in WT mice and, unexpectedly, the rates of protein synthesis are higher in MEFs derived from $\mathrm{rpS}^{\mathrm{p}-{ }^{-/}}$mice compared to those derived from WT mice ${ }^{10}$. Therefore, it is far from clear what role rpS6 phosphorylation plays in the regulation of general protein synthesis. GLP1 also stimulates $\beta$-cell proliferation, growth, differentiation and inhibits apoptosis ${ }^{14}$. Therefore, it is tempting to speculate that PKA-dependent site specific phosphorylation of rpS6 in response to GLP1 plays an important role in the translational regulation of a specific subset of transcripts involved in one or more of these processes. Indeed, evidence from $\mathrm{rpS}^{\mathrm{p}-{ }^{--}}$and $\mathrm{S} 6 \mathrm{~K} 1^{-/-}$mice demonstrates that the phosphorylation of rpS6 plays a particularly important role in the growth and function of the pancreatic $\beta$-cell ${ }^{8 ; 10}$. The $\beta$-cells from the $\mathrm{rpS6}^{\mathrm{p}-{ }_{-}}$mice are smaller in size but total $\beta$-cell mass is unaffected due to increased $\beta$-cell number ${ }^{10}$. Yet both pancreatic insulin content and circulating levels of insulin in $\mathrm{rpS}^{\mathrm{p}-{ }^{-l}}$ mice is half of that found in WT mice ${ }^{10}$. Although similar phenotypic changes were observed in the $\mathrm{S} 6 \mathrm{~K} 1^{-1-}$ mice, decreases in insulin were attributed to a decrease in $\beta$-cell mass/volume ${ }^{8}$. As cAMP signalling to $\mathrm{rpS6}$ is unaffected in $\mathrm{S} 6 \mathrm{~K}^{-1-}$ mice, PKA-dependent phosphorylation of rpS6 cannot compensate for the loss of S6K1. However, PKA dependent phosphorylation of rpS6 may still play a role in stimulating increases in $\beta$-cell mass in response to specific cues. Moreover, the volume of individual $\beta$-cells from $\mathrm{rpS}^{\mathrm{p}-\mathrm{r}}$ mice is $35 \%$ smaller than its wild type counterpart ${ }^{10}$, whereas the volume of individual $\beta$-cells from S6 $61^{-1-}$ mice is $24 \%$ smaller than its wild type counterpart ${ }^{8}$. Unfortunately, there is no data available on the volume of $\beta$-cells from S6 $61^{-1-} / 2^{-/-}$mice but $\beta$-cell size is unaffected in $\mathrm{S} 6 \mathrm{~K} 2^{-/-}$mice. Therefore, the increased $\beta$-cell volume observed in S6K $1^{-/-}$mice compared to the $\beta$-cells from $\mathrm{rpS}^{\mathrm{p}^{-/-}}$ may be due to the maintained phosphorylation of rpS6 on Ser(235/236), possibly mediated by PKA. However, it is as well conceivable that PKA-dependent phosphorylation of rpS6 may play a role distinct from translation as a number of ribosomal proteins have been shown to have extra ribosomal functions ${ }^{43}$.

PP2A is a major Ser/Thr phosphatase consisting of a catalytic (c) and scaffolding (A) subunit (reviewed in ${ }^{17}$ ). It's substrate specificity and subcellular localization is mediated by regulatory B subunits. In yeast, Tap42, when phosphorylated by TOR, binds to and inhibits PP2Ac. Rapamycin treatment causes dissociation of this complex, resulting in PP2Ac directing its activity towards downstream targets of TOR. In mammalian cells, PP2Ac has been found to associate with a homolog 
of Tap42 called $\alpha 4$, also in a rapamycin-sensitive fashion. Moreover, in Jurkat cells, PP2A is activated by rapamycin treatment or nutrient deprivation, resulting in a decrease in the phosphorylation of downstream targets of mTORC1 ${ }^{44}$. PP2A is likely to play an important role in nutrient regulated $\beta$ cell function and nutrient secretagogues such as glucose inhibit PP2A in $\beta$-cells (reviewed in ${ }^{45}$ ). Interestingly, we provide evidence that a phosphatase, likely PP2A, is also activated by inhibition of mTORC1 in $\beta$-cells. We show that the activation of this phosphatase in response to rapamycin results in the dephosporylation of rpS6 specifically on Ser(235/236). We suggest that the inhibition of mTORC1 caused by a decrease in glucose concentration would activate PP2A and play an important role in $\beta$-cell function.

In conclusion, we have identified PKA as a third in vivo rpS6 kinase that specifically phosphorylates rpS6 on Ser(235/236) in response to GLP1 in pancreatic $\beta$-cells. This is likely to be a paradigm for cAMP dependent signalling to $\mathrm{rpS} 6$ in response to other physiological stimuli which induce increases in cAMP not only in $\beta$-cells but in other cell types. This work also provides a potentially important link between cAMP-dependent signalling and protein synthesis.

\section{Materials and Methods}

Reagents. Foetal calf serum was purchased from Invitrogen. $\left[{ }^{32} \mathrm{P}\right]-\gamma \mathrm{ATP}$ was purchased from Amersham Pharmacia Biotech. All other chemicals and reagents were purchased from Sigma unless otherwise stated. Penatratin coupled PKI peptides (PKIRR:TTYADFIASGRTGRRNAIDHDAARQIKIWFQNRRMKWKK and PKIAA:TTYADFIASGRTGAANAIDHDAARQIKIWFQNRRMKWKK ) were designed by Professor Chris Proud, University of Southampton, UK and generated by Dr G. Bloomberg, Department of Biochemistry, Bristol university, UK. Adenovirus expressing MKP3 was kindly provided by Professor Phillip Pratt, Department of Pharmacology and Toxicology, Medical College of Wisconsin, USA.

Cell Culture and Treatments. In this study, MIN6 cells (kindly provided by Prof. Jun-Ichi Miyazaki) were used between passages 25-50 at $\sim 80 \%$ confluence. MIN6 cells were grown in DMEM containing $25 \mathrm{mM}$ glucose supplemented with $15 \%$ heat-inactivated foetal calf serum, $100 \mu \mathrm{g} / \mathrm{ml}$ streptomycin, 100units/ml penicillin sulphate, $75 \mu \mathrm{M} \quad \beta$-mercaptoethanol and $40 \mathrm{mM}$ sodium bicarbonate, equilibrated with $5 \% \mathrm{CO}_{2}, 95 \%$ air at $37^{\circ} \mathrm{C}$. Prior to treatment, cells were serum starved overnight. The medium was then removed, the cells were washed twice with modified HEPESbalanced Krebs-Ringer bicarbonate buffer (KRB) $((115 \mathrm{mM} \mathrm{NaCl}, 5 \mathrm{mM} \mathrm{KCl}, 10 \mathrm{mM} \mathrm{NaHCO}$, $2.5 \mathrm{mM} \mathrm{MgCl} 2,2.5 \mathrm{mM} \mathrm{CaCl} 2,20 \mathrm{mM}$ HEPES, pH7.4 supplemented with 0.5X MEM amino acids solution (50X stock from Sigma), 0.5X MEM non-essential amino acids solution (100X stock from Sigma), and $0.5 \mathrm{X} \mathrm{L}$-glutamine (100X stock from Sigma)) and then incubated for $1 \mathrm{~h}$ at $37^{\circ} \mathrm{C}$ in KRB prior to incubation in KRB or KRB containing $20 \mathrm{mM}$ glucose or $20 \mathrm{mM}$ glucose plus 10nM GLP1 for a further hour at $37^{\circ} \mathrm{C}$ (unless otherwise stated). Full details of treatments are provided in the figure legends. After treatment, the cells were washed with ice cold PBS and then lysed by the addition of ice-cold lysis buffer containing $1 \%$ triton, $10 \mathrm{mM} \beta$-glycerophosphate, $50 \mathrm{mM}$ tris- $\mathrm{HCl} \mathrm{pH} 7.5,1 \mathrm{mM}$ EDTA, $1 \mathrm{mM}$ EGTA, $1 \mathrm{mM}$ sodium orthovanadate, $1 \mathrm{mM}$ benzamidine- $\mathrm{HCl}, \quad 0.2 \mathrm{mM}$ phenylmethylsulfonyl fluoride, $1 \mu \mathrm{g} / \mathrm{ml}$ each of leupeptin and pepstatin, $0.1 \% \beta$-mercaptoethanol and $50 \mathrm{mM}$ sodium fluoride (unless otherwise stated). The lysates were then centrifuged for $10 \mathrm{~min}$ at $16000 \mathrm{x}$ g. The supernatants were kept and total protein concentrations were determined by the Bradford assay (Bio-Rad). The protein lysates were stored at $-80^{\circ} \mathrm{C}$ until further analysis.

Islet Isolation and Culturing. Pancreatic islets were isolated from 200-250g male Sprague Dawley rats by collagenase digestion and Histopaque density gradient centrifugation as previously described ${ }^{46}$. Islets were cultured for $16 \mathrm{~h}$ in RPMI 1640 containing $5.6 \mathrm{mM}$ glucose, $100 \mathrm{units} / \mathrm{ml}$ penicillin and $100 \mu \mathrm{g} / \mathrm{ml}$ streptomycin. Prior to treatment, islets were washed twice with KRB buffer minus glucose. The cells were then incubated for $2 \mathrm{~h}$ at $37^{\circ} \mathrm{C}$ in $\mathrm{KRB}$ buffer containing $2 \mathrm{mM}$ glucose prior to incubation in KRB buffer containing 2 or $20 \mathrm{mM}$ glucose for the times indicated in the figure legends 
(full details of treatments are provided in the figure legends). After treatment, islets were collected by centrifugation for $1 \mathrm{~min}$ at $200 \mathrm{x} g$ and lysed by the addition of ice-cold lysis buffer.

Construction of Plasmids. pGST-S6AA, where Ser235 and Ser236 were changed to alanines, and pGST-S6DD, where Ser235 and Ser236 were changed to aspartic acid, were generated by sitedirected mutagenesis using pGST-S6 (a bacterial expression plasmid encoding GST fused to the Cterminal of rat rpS6) as template. Site-Directed mutagenesis was carried out using the QuikChange mutagenesis kit according to the manufacturer's instructions (Stratagene).

Protein Expression. The pGST-S6 constructs were transformed into Escherichia coli (strain Rosetta BL21) and grown in Luria-Bertani Broth (LB) at $37^{\circ} \mathrm{C}$. Protein production was initiated after the cells had reached $\mathrm{OD}_{600}$ of 0.9 by the addition of $1 \mathrm{mM}$ isopropyl $\beta$-D thiogalactopyranoside (IPTG). After $3 \mathrm{~h}$, the cells were collected by centrifugation for 15 minutes at $5000 \mathrm{x} g$ at $4^{\circ} \mathrm{C}$. The cells were then resuspended in $2-5 \mathrm{ml}$ of lysis buffer $(5 \%$ glycerol $(\mathrm{v} / \mathrm{v}), 1 \mathrm{M} \mathrm{KCl}, 20 \mathrm{mM}$ Tris $\mathrm{HCl} \mathrm{pH} 8.0,3 \mathrm{mM}$ $\mathrm{MgCl}_{2}, 5 \mathrm{mM} \beta$-mercaptoethanol, $5 \mathrm{mM} \mathrm{NaF}, 1 \mathrm{mM}$ PMSF, leupeptin $(1 \mu \mathrm{g} / \mathrm{ml})$, pepstatin $(1 \mu \mathrm{g} / \mathrm{ml})$, $0.1 \%$ triton) per gram of pelleted cells (wet weight) and then sonicated. Bacterial debris was removed by centrifugation at $16000 \mathrm{x}$ g for 15 minutes at $4^{\circ} \mathrm{C}$. The fusion proteins were then isolated from the supernatants using glutathione Sepharose beads (Amersham) according to the manufacturer's instructions. The proteins were eluted using Elution Buffer (lysis buffer containing $20 \mathrm{mM}$ reduced

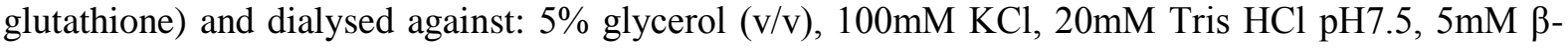
mercaptoethanol, $5 \mathrm{mM}$ NaF, $1 \mathrm{mM}$ PMSF, $1 \mu \mathrm{g} / \mathrm{ml}$ leupeptin, $1 \mu \mathrm{g} / \mathrm{ml}$ pepstatin.

S6K1 and S6K2 Kinase Assay. MIN6 cells were lysed in lysis buffer containing 50mM HEPES pH $7.5,150 \mathrm{mM} \mathrm{NaCl}, 1 \%(\mathrm{v} / \mathrm{v})$ Nonidet P-40, $2 \mathrm{mM}$ EDTA, 50mM sodium fluoride, $10 \mathrm{mM}$ sodium pyrophosphate, $1 \mathrm{mM}$ sodium orthovanadate, $0.1 \mu \mathrm{g} / \mathrm{ml}$ of leupeptin, $0.1 \mu \mathrm{g} / \mathrm{ml}$ of pepstatin, $1 \mathrm{mM}$ phenylmethylsulfonyl fluoride, and $3 \mathrm{mM}$ benzamidine. Whole-cell extracts were centrifuged at 16000 $\mathrm{x} g$ for $10 \mathrm{~min}$ at $4^{\circ} \mathrm{C}$, and endogeneous S6K1 or S6K2 were immunoprecipitated with the anti-S6K1 or anti-S6K2 antibody immobilized on protein G-Sepharose beads. Immune complexes were washed three times with lysis buffer followed by a single wash with kinase assay buffer (50mM HEPES pH $7.5,10 \mathrm{mM} \mathrm{MgCl} 2,1 \mathrm{mM}$ dithiothreitol, $10 \mathrm{mM} \beta$-glycerophosphate). The kinase reaction was initiated by resuspending the beads in $25 \mu \mathrm{l}$ of kinase assay buffer supplemented with $1 \mu \mathrm{M}$ PKI (Calbiochem), $50 \mu \mathrm{M}$ ATP, $1 \mu \mathrm{Ci}$ of $\left[{ }^{32} \mathrm{P}\right] \gamma \mathrm{ATP}$ and $6 \mu \mathrm{g}$ of GST-S6. The reaction was carried out at $30^{\circ} \mathrm{C}$ for $10 \mathrm{~min}$ and terminated by the addition of Laemmli sample buffer. Samples were boiled for $5 \mathrm{~min}$ at $100^{\circ} \mathrm{C}$ and separated by SDS-PAGE. ${ }^{32}$ P-labelled GST-S6 visualised by autoradiography. Labelled GST-S6 'bands' were excised from the gel and ${ }^{32} \mathrm{P}$-incorporation into GST-S6 measured by Cherenkov counting.

cAMP-dependent Kinase Assays Using GST-S6 as Substrate. In vitro phosphorylation of the GST-S6 and mutants by the PKA catalytic subunit (PKAc) was carried out according to the manufacturer's recommendations (Upstate Biotechnology, Inc.). Briefly, reactions containing $3 \mu \mathrm{g}$ GST-S6, $1 \mu \mathrm{Ci}$ of $\left[\gamma_{-}{ }^{32} \mathrm{P}\right] \mathrm{ATP}, 5 \mu \mathrm{l}$ ADBI buffer (40mM MOPS $\mathrm{pH} 7.0,1 \mathrm{mM}$ EDTA) and recombinant PKA diluted in $20 \mathrm{mM}$ MOPS pH7.0, $1 \mathrm{mM}$ EDTA, $0.01 \%$ Brij-35, $5 \%$ glycerol, $0.1 \% \beta$-mercaptoethanol, $1 \mathrm{mg} / \mathrm{ml}$ BSA were incubated at $30{ }^{\circ} \mathrm{C}$ for $10 \mathrm{~min}$ under constant agitation. The kinase reactions were stopped by addition of Laemmli sample buffer. For rpS6 kinase assays using cell lysates, MIN6 cells were treated as described above and in the figure legends. Kinase reactions containing $20 \mu \mathrm{g}$ cell lysates, $3 \mu \mathrm{g}$ of the recombinant GST-S6 (or GST-S6AA) coupled to GST beads (GE Healthcare), $1 \mu \mathrm{Ci}$ of $\left[{ }^{32} \mathrm{P}\right]-\gamma \mathrm{ATP}, 12 \mu \mathrm{M} \mathrm{MgCl} 2,12 \mu \mathrm{M}$ Tris-HCl, $\mathrm{pH} 7.5$, in the absence or presence of $1 \mu \mathrm{M}$ PKI, were incubated at $30{ }^{\circ} \mathrm{C}$ for $1 \mathrm{~h}$ under constant agitation. GST beads were washed twice in lysis buffer prior to the addition of Laemmli sample buffer.

In all cases, samples were boiled for $5 \mathrm{~min}$ at $100^{\circ} \mathrm{C}$ and the proteins separated by SDS-PAGE. ${ }^{32} \mathrm{P}-$ labelled GST-S6 was visualised by autoradiography. Labelled GST-S6 'bands' were then excised from the gel and ${ }^{32} \mathrm{P}$-incorporation into GST-S6 measured by Cherenkov counting. 
SDS-PAGE and Western Blotting. SDS-PAGE and Western blotting were performed as described previously ${ }^{47}$. Anti-phospho: Erk Thr202/Tyr204, rpS6 Ser235/Ser236, rpS6 Ser240/Ser244, PKB Ser473, AMPK Thr172, S6K1 Thr389, Acetyl CoA carboxylase (ACC) Ser79, 4EBP1 Ser65 antibodies as well as anti-PKB, Erk2, rpS6, Rsk1, AMPK and S6K1 were purchased from Cell Signalling Technologies, MA, USA. Anti-myc(9E10) antibody was purchased from Sigma. AntiPKC $\alpha, \gamma$ and $\varepsilon$ antibodies were purchased from Transduction Laboratories. Anti-S6K2 antibody was kindly provided by Professor Ivan Gout (University College London, Institute of Structural and Molecular Biology, London, UK).

Acknowledgements. We would also like to thank Professors Ivan Gout, Phillip Pratt and Chris Proud for generously providing reagents.

Funding. CEJM was supported by an MRC studentship and JX was supported by a CONACYT scholarship from Mexico (scholarship number 206710). TPH and EG were supported by a Wellcome Trust Project Grant WT081268MA (awarded to TPH).

Abbreviations. GLP1, glucagon like peptide 1; MIN6, mouse insulinoma cell line 6; PAGE, polyacrylamide gel electrophoresis; KRB, Krebs-Ringer bicarbonate buffer; S6K, ribosomal protein S6 kinase, rpS6, ribosomal protein S6; Erk, Extracellular regulated kinase, PKB Protein kinase B; PKC, protein Kinase C; PKA, Protein kinase A/cAMP-dependent protein kinase; AMPK, AMP activated protein kinase. Rsk, p90 ribosomal S6 kinase; mTORC1, mammalian target of Rapamycin complex 1;4E-BP, eIF4E binding protein; ACC, Acetyl CoA carboxylase; MKP3, Mitogen-activated protein kinase phosphatase 3; IBMX, isobutylmethylxanthine; PBS, phosphate buffered saline.

1. Wool, I. G. (1979). The structure and function of eukaryotic ribosomes. Annu Rev Biochem 48, 719-54.

2. Taylor DJ., J. F., and Goss Kinzy T. (2007). Translational Control in Biology and Medicine (Methews MB., S. N., and Hershey JWB., Ed.), Cold Spring Harbor Laboratory Press, New York.

3. Stewart, M. J. \& Thomas, G. (1994). Mitogenesis and protein synthesis: a role for ribosomal protein S6 phosphorylation? Bioessays 16, 809-15.

4. $\quad$ Ferrari, S., Bandi, H. R., Hofsteenge, J., Bussian, B. M. \& Thomas, G. (1991). Mitogen-activated 70K S6 kinase. Identification of in vitro $40 \mathrm{~S}$ ribosomal S6 phosphorylation sites. Journal of Biological Chemistry 266, 22770-22775.

5. Bandi, H. R., Ferrari, S., Krieg, J., Meyer, H. E. \& Thomas, G. (1993). Identification of $40 \mathrm{~S}$ ribosomal protein S6 phosphorylation sites in Swiss mouse 3T3 fibroblasts stimulated with serum. J Biol Chem 268, 4530-3.

6. Montagne, J., Stewart, M. J., Stocker, H., Hafen, E., Kozma, S. C. \& Thomas, G. (1999). Drosophila S6 kinase: a regulator of cell size. Science 285, 2126-9.

7. Shima, H., Pende, M., Chen, Y., Fumagalli, S., Thomas, G. \& Kozma, S. C. (1998). Disruption of the $\mathrm{p} 70^{\mathrm{S} 6 \mathrm{k}} / \mathrm{p} 85^{\mathrm{S} 6 \mathrm{k}}$ gene reveals a small mouse phenotype and a new functional S6 kinase. EMBO Journal 17, 6649-6659.

8. Pende, M., Kozma, S. C., Jaquet, M., Oorschot, V., Burcelin, R., Le Marchand-Brustel, Y., Klumperman, J., Thorens, B. \& Thomas, G. (2000). Hypoinsulinaemia, glucose intolerance and diminished beta-cell size in S6K1deficient mice. Nature 408, 994-7.

9. Pende, M., Um, S. H., Mieulet, V., Sticker, M., Goss, V. L., Mestan, J., Mueller, M., Fumagalli, S., Kozma, S. C. \& Thomas, G. (2004). S6K1(-/)/S6K2(-/-) mice exhibit perinatal lethality and rapamycin-sensitive 5'-terminal oligopyrimidine mRNA translation and reveal a mitogen-activated protein kinase-dependent S6 kinase pathway. Mol Cell Biol 24, 3112-24. 
10. Ruvinsky, I., Sharon, N., Lerer, T., Cohen, H., Stolovich-Rain, M., Nir, T., Dor, Y., Zisman, P. \& Meyuhas, O. (2005). Ribosomal protein S6 phosphorylation is a determinant of cell size and glucose homeostasis. Genes Dev 19, 2199-211.

11. Roux, P. P., Shahbazian, D., Vu, H., Holz, M. K., Cohen, M. S., Taunton, J., Sonenberg, N. \& Blenis, J. (2007). RAS/ERK signaling promotes site-specific ribosomal protein S6 phosphorylation via RSK and stimulates cap-dependent translation. J Biol Chem 282, 14056-64.

12. Alcorta, D. A., Crews, C. M., Sweet, L. J., Bankston, L., Jones, S. W. \& Erikson, R. L. (1989). Sequence and expression of chicken and mouse rsk: homologs of Xenopus laevis ribosomal S6 kinase. Mol Cell Biol 9, 3850-9.

13. Meyuhas, O. (2000). Synthesis of the translational apparatus is regulated at the translational level. Eur J Biochem 267, 6321-30.

14. Holst, J. J. (2007). The physiology of glucagon-like peptide 1. Physiol Rev 87, 1409-39.

15. Kwon, G., Marshall, C. A., Pappan, K. L., Remedi, M. S. \& McDaniel, M. L. (2004). Signaling elements involved in the metabolic regulation of mTOR by nutrients, incretins, and growth factors in islets. Diabetes 53 Suppl 3, S22532.

16. Ishihara, H., Asano, T., Tsukuda, K., Katagiri, H., Inukai, K., Anai, M., Kikuchi, M., Yazaki, Y., Miyazaki, J. I. \& Oka, Y. (1993). Pancreatic beta cell line MIN6 exhibits characteristics of glucose metabolism and glucosestimulated insulin secretion similar to those of normal islets. Diabetologia 36, 1139-45.

17. Janssens, V. \& Goris, J. (2001). Protein phosphatase 2A: a highly regulated family of serine/threonine phosphatases implicated in cell growth and signalling. Biochem J 353, 417-39.

18. El-Kholy, W., Macdonald, P. E., Lin, J. H., Wang, J., Fox, J. M., Light, P. E., Wang, Q., Tsushima, R. G. \& Wheeler, M. B. (2003). The phosphatidylinositol 3-kinase inhibitor LY294002 potently blocks K(V) currents via a direct mechanism. Faseb J 17, 720-2.

19. Gomez, E., Pritchard, C. \& Herbert, T. P. (2002). cAMP-dependent Protein Kinase and $\mathrm{Ca} 2+$ Influx through L-type Voltage-gated Calcium Channels Mediate Raf-independent Activation of Extracellular Regulated Kinase in Response to Glucagon-like Peptide-1 in Pancreatic beta-Cells. J. Biol. Chem. 277, 48146-48151.

20. Gleason, C. E., Lu, D., Witters, L. A., Newgard, C. B. \& Birnbaum, M. J. (2007). The role of AMPK and mTOR in nutrient sensing in pancreatic betacells. J Biol Chem 282, 10341-51.

21. Dokladda, K., Green, K. A., Pan, D. A. \& Hardie, D. G. (2005). PD98059 and U0126 activate AMP-activated protein kinase by increasing the cellular AMP:ATP ratio and not via inhibition of the MAP kinase pathway. FEBS Lett 579, 236-40.

22. Rolfe, M., McLeod, L. E., Pratt, P. F. \& Proud, C. G. (2005). Activation of protein synthesis in cardiomyocytes by the hypertrophic agent phenylephrine requires the activation of ERK and involves phosphorylation of tuberous sclerosis complex 2 (TSC2). Biochem J 388, 973-84.

23. Zhou, F. F., Xue, Y., Chen, G. L. \& Yao, X. (2004). GPS: a novel group-based phosphorylation predicting and scoring method. Biochem Biophys Res Commun 325, 1443-8. 
24. Wettenhall, R. E., Erikson, E. \& Maller, J. L. (1992). Ordered multisite phosphorylation of Xenopus ribosomal protein S6 by S6 kinase II. J Biol Chem 267, 9021-7.

25. Wettenhall, R. E. \& Cohen, P. (1982). Isolation and characterisation of cyclic AMP-dependent phosphorylation sites from rat liver ribosomal protein S6. FEBS Lett 140, 263-9.

26. Kim, C., Xuong, N. H. \& Taylor, S. S. (2005). Crystal structure of a complex between the catalytic and regulatory (RIalpha) subunits of PKA. Science 307, 690-6.

27. Gressner, A. M. \& Wool, I. G. (1974). The phosphorylation of liver ribosomal proteins in vivo. Evidence that only a single small subunit protein (S6) is phosphorylated. J Biol Chem 249, 6917-25.

28. Krieg, J., Hofsteenge, J. \& Thomas, G. (1988). Identification of the $40 \mathrm{~S}$ ribosomal protein $\mathrm{S} 6$ phosphorylation sites induced by cycloheximide. J Biol Chem 263, 11473-7.

29. Krieg, J., Olivier, A. R. \& Thomas, G. (1988). Analysis of 40S ribosomal protein S6 phosphorylation during the mitogenic response. Methods Enzymol 164, 575-81.

30. Erikson, R. L. (1991). Structure,expression, and regulation of protein kinases involved in the phosphorylation of ribosomal protein S6. Journal of Biological Chemistry 266, 6007-6010.

31. Price, D. J., Grove, J. R., Calvo, V., Avruch, J. \& Bierer, B. E. (1992). Rapamycin-induced inhibition of the 70-kilodalton S6 protein kinase. Science 257, 973-977.

32. Brown, E. J., Beal, P. A., Keith, C. T., Chen, J., Shin, T. B. \& Schreiber, S. L. (1995). Control of p70 s6 kinase by kinase activity of FRAP in vivo. Nature 377, 441-6.

33. Filippa, N., Sable, C. L., Filloux, C., Hemmings, B. \& Van Obberghen, E. (1999). Mechanism of protein kinase B activation by cyclic AMP-dependent protein kinase. Mol Cell Biol 19, 4989-5000.

34. Mei, F. C., Qiao, J., Tsygankova, O. M., Meinkoth, J. L., Quilliam, L. A. \& Cheng, X. (2002). Differential signaling of cyclic AMP: opposing effects of exchange protein directly activated by cyclic AMP and cAMP-dependent protein kinase on protein kinase B activation. J Biol Chem 277, 11497-504.

35. Moule, S. K., Welsh, G. I., Foulstone, E. J., Heesom, K., Edgell, N., Proud, C. G. \& Denton, R. M. (1997). Regulation of protein kinase B and glycogen synthase kinase 3 by insulin and $\beta$-adrenergic agonists in rat epididymal fat cells. Activation of protein kinase B by wortmannin-sensitive and- insensitive mechanisms. Journal of Biological Chemistry 272, 7713-7719.

36. Brennesvik, E. O., Ktori, C., Ruzzin, J., Jebens, E., Shepherd, P. R. \& Jensen, J. (2005). Adrenaline potentiates insulin-stimulated PKB activation via cAMP and Epac: implications for cross talk between insulin and adrenaline. Cell Signal 17, 1551-9.

37. Manning, B. D., Tee, A. R., Logsdon, M. N., Blenis, J. \& Cantley, L. C. (2002). Identification of the tuberous sclerosis complex-2 tumor suppressor gene product tuberin as a target of the phosphoinositide 3-kinase/akt pathway. Mol Cell 10, 151-62.

38. Stork, P. J. \& Schmitt, J. M. (2002). Crosstalk between cAMP and MAP kinase signaling in the regulation of cell proliferation. Trends Cell Biol 12, 258-66. 
39. Roux, P. P., Ballif, B. A., Anjum, R., Gygi, S. P. \& Blenis, J. (2004). Tumorpromoting phorbol esters and activated Ras inactivate the tuberous sclerosis tumor suppressor complex via p90 ribosomal S6 kinase. Proc Natl Acad Sci U $S$ A 101, 13489-94.

40. Roux, P. P. \& Blenis, J. (2004). ERK and p38 MAPK-activated protein kinases: a family of protein kinases with diverse biological functions. Microbiol Mol Biol Rev 68, 320-44.

41. Ma, L., Chen, Z., Erdjument-Bromage, H., Tempst, P. \& Pandolfi, P. P. (2005). Phosphorylation and functional inactivation of TSC2 by Erk implications for tuberous sclerosis and cancer pathogenesis. Cell 121, 179-93.

42. Alarcon, C., Wicksteed, B. \& Rhodes, C. J. (2006). Exendin 4 controls insulin production in rat islet beta cells predominantly by potentiation of glucosestimulated proinsulin biosynthesis at the translational level. Diabetologia 49, 2920-9.

43. Wool, I. G. (1996). Extraribosomal functions of ribosomal proteins. Trends Biochem Sci 21, 164-5.

44. Peterson, R. T., Desai, B. N., Hardwick, J. S. \& Schreiber, S. L. (1999). Protein phosphatase 2A interacts with the $70-\mathrm{kDa}$ S6 kinase and is activated by inhibition of FKBP12-rapamycinassociated protein. Proc Natl Acad Sci U $S$ A 96, 4438-42.

45. Kowluru, A. (2005). Novel regulatory roles for protein phosphatase-2A in the islet beta cell. Biochem Pharmacol 69, 1681-91.

46. Guest, P. C., Rhodes, C. J. \& Hutton, J. C. (1989). Regulation of the biosynthesis of insulin-secretory-granule proteins. Co-ordinate translational control is exerted on some, but not all, granule matrix constituents. Biochem J 257, 431-7.

47. Herbert, T. P., Kilhams, G. R., Batty, I. H. \& Proud, C. G. (2000). Distinct Signalling Pathways Mediate Insulin and Phorbol Ester-stimulated Eukaryotic Initiation Factor 4F Assembly and Protein Synthesis in HEK 293 Cells. J Biol Chem 275, 11249-11256.

\section{Figure legends}

Figure 1: Role of PI3K in rpS6 phosphorylation.

MIN6 cells were preincubated in KRB for $1 \mathrm{~h}$. Cells were then treated in KRB for $1 \mathrm{~h}$ with a.) $20 \mathrm{mM}$ glucose, b.) $20 \mathrm{mM}$ glucose plus $10 \mathrm{nM}$ GLP1 or c.) $10 \mu \mathrm{M}$ forskolin in the presence or absence of LY294002 or wortmannin. Proteins were resolved on SDS-PAGE and Western blotted using antisera against phosphorylated (P) rpS6 on Ser(235/236) (P-rpS6 S235/236) and Ser(240/244) (P-rpS6 S240/244), P-PKB Ser473, S6K1 and, as a loading control, Erk2. aii., bii, cii) The effects of $20 \mu \mathrm{M}$ LY294002 or $100 \mathrm{nM}$ wortmannin on the phosphorylation of rpS6 on Ser(235/236) were quantified by densitometric analysis. d. and e.) MIN6 cells were incubated in KRB for $1 \mathrm{~h}$ with $20 \mathrm{mM}$ glucose plus $10 \mathrm{nM}$ GLP1 in the presence or absence of $20 \mu$ M LY294002. Lysates were subjected to a d.) S6K1 and e.) S6K2 kinase assay using GST-S6 as substrate and reactions separated by SDS-PAGE and (di. and ei.) visualised by autoradiography (top panel) and Coomassie blue staining (bottom panel). dii. and eii.) Incorporation of ${ }^{32} \mathrm{P}$ into GST-S6 expressed as percentage of control. All results are representative of independent experiments and shown as means $\pm \mathrm{SE} ; n=3$. ${ }^{*} P<0.05$ using a one-way ANOVA. P value obtained using a one-way ANOVA followed by Bonferroni adjustment.

Figure 2: Role of mTORC1 in cAMP-dependent phosphorylation of rpS6. 
MIN6 cells were preincubated in KRB for $1 \mathrm{~h}$, and were then treated for a further $1 \mathrm{~h}$ in KRB containing glucose $20 \mathrm{mM}$ (glu), 20mM glucose plus 10nM GLP1 (GLP1) or 10 $\mu \mathrm{M}$ forskolin (Fsk). a.) rapamycin $(200 \mathrm{nM})$, b.) okadaic acid or cantharidin were added $30 \mathrm{~min}$ before treatment. Cell lysates were separated on SDS/PAGE and subjected to immunoblotting with antisera against phosphorylated (P) rpS6 Ser(235/236) and Ser(240/244), P-PKB Ser(473), and as loading control total Erk2. (aii) Phosphorylation of rpS6 on $\operatorname{Ser}(235 / 236)$ was quantified by densitometric analysis. Results shown as means \pm SE; $n=3$. $* P<0.05$, ${ }^{*} P<$ 0.01 . $P$ values obtained using a one-way ANOVA. $P$ value obtained using a one-way ANOVA followed by Bonferroni adjustment. All results are representative of 3 independent experiments.

Figure 3: rpS6 phosphorylation on $\operatorname{Ser}(235 / 236)$ is independent of Rsk.

a.) MIN6 cells were uninfected or (b.) infected with the recombinant adenovirus expressing MKP3 (Ad MKP3) for 48h. Cells were preincubated in KRB for $1 \mathrm{~h}$, and were then treated for a further $1 \mathrm{~h}$ in KRB containing $20 \mathrm{mM}$ glucose, $20 \mathrm{mM}$ glucose plus $10 \mathrm{nM}$ GLP1 or $1 \mu \mathrm{M}$ TPA. $1.25 \mu \mathrm{M}$ PD183452, $20 \mu \mathrm{M}$ LY294002 or both were added 30 min before treatment with glucose and GLP1. Cell lysates were separated on SDS/PAGE and subjected to immunoblotting with antisera against phosphorylated (P) rpS6 Ser(235/236) and Ser(240/244), (P)AMPK Thr(172), (P)Erk, (P)ACC Ser79, (P)4E-BP1 Ser65, Rsk, S6K1 and as loading controls, total rpS6 and AMPK. Quantified data from phospho-rpS6 Ser(235/236) blots is shown below as means $\pm \mathrm{SE} ; n=4$. No statistical significance was obtained among the samples treated with GLP1 in the presence or absence of PD183452, LY294002 or both. ${ }^{*} P<0.05$. $\mathrm{P}$ value obtained using a one-way ANOVA followed by Bonferroni adjustment.

Figure 4: PKC is not involved in GLP1 mediated rpS6 phosphorylation.

a.) MIN6 cells were preincubated for $1 \mathrm{~h}$ in KRB. Cells were then treated for a further $1 \mathrm{~h}$ in KRB containing $20 \mathrm{mM}$ glucose, $20 \mathrm{mM}$ glucose plus $10 \mathrm{nM}$ GLP1 or $1 \mu \mathrm{M}$ TPA. BIM $(1 \mu \mathrm{M})$, Ro320432 $(1 \mu \mathrm{M})$ and Gö6976 $(1 \mu \mathrm{M})$, or LY294002 $(20 \mu \mathrm{M})$ were added 30 min before treatment with glucose plus GLP1 or TPA. a.) and b.) Cells were also treated for $16 \mathrm{~h}$ with TPA (O/N TPA). Lysates were separated on SDS-PAGE and Western blotted using antisera specific to phosphorylated (P) rpS6 Ser(235/236) and Ser(240/244), (P)Erk, and to total rpS6 and $\mathrm{PKC} \alpha, \gamma$, and $\varepsilon$. Results shown are representative of at least three independent experiments.

\section{Figure 5: PKA selectively phosphorylates rpS6 on Ser235/236 in vitro.}

The PKA activity was determined by in vitro kinase assay using GST-S6, or GST-S6AA as substrates and PKAc as enzyme. Samples were resolved by SDS-PAGE. ai) Top Panels: autoradiographs of ${ }^{32} \mathrm{P}$ incorporation into substrate Bottom Panels: Gel stained with Coomassie blue. aii) ${ }^{32} \mathrm{P}$ incorporation into substrate quantified by Cherenkov counting. Data is presented as means \pm SE; $n=6$ for GST-S6, or 3 for GST-S6AA and GST-S6DD. b.) Samples from in vitro kinase assays using either PKAc or S6K1 as enzyme and GST-S6 as substrate or, as control, lysates from MIN6 cell treated with GLP1, were separated by SDSPAGE and Western blotted using antisera against phosphorylated (P) rpS6 (Ser235/236) and Ser(240/244), and total rpS6.

\section{Figure 6: Evidence that PKA phosphorylates rpS6 in vivo.}

MIN6 cells were pre-incubated in KRB for $1 \mathrm{~h}$. Cells were then treated for a further $1 \mathrm{~h}$ in KRB containing: $20 \mathrm{mM}$ glucose, $20 \mathrm{mM}$ glucose plus $10 \mathrm{nM}$ GLP1 or $10 \mu \mathrm{M}$ forskolin. (a) $2.5 \mu \mathrm{M}$ PD183452 and $20 \mu \mathrm{M}$ LY294002 were added 30min before treatment with glucose plus GLP1 or forskolin. The kinase assays were performed on cell lysates $(20 \mu \mathrm{g})$ in the presence or absence of $1 \mu \mathrm{M}$ PKI, using the recombinant proteins GST-S6 and GST-S6AA as substrates. GST-S6 and GST-S6AA were separated by SDS-PAGE Top panel: ${ }^{32} \mathrm{P}-$ incorporation into substrate visualised by autoradiography. Bottom panel: the substrate visualised by Coomassie blue-staining. b.) H89, c.) MDL12,330A or d.) $50 \mu \mathrm{M}$ Pentratinlinked $\mathrm{PKI}_{\mathrm{RR}}$ or as control $\mathrm{PKI}_{\mathrm{AA}}$ were added $30 \mathrm{~min}$ prior to treatment. Proteins were resolved on SDS-PAGE and Western blotted using antisera against phosphorylated (P) rpS6 
Ser(235/236) and Ser(240/244), S6K1 and, as loading control, Erk2. All results are representative of at least 3 independent experiments.

Figure 7: Evidence that PKA phosphorylates rpS6 in Islets of Langerhans.

Islets were preincubated in KRB supplemented with $2 \mathrm{mM}$ Glucose for $1 \mathrm{~h}$. Islets were then treated in KRB for $1 \mathrm{~h}$ with: $20 \mathrm{mM}$ glucose, $20 \mathrm{mM}$ glucose plus $10 \mathrm{nM}$ GLP1 or $10 \mu \mathrm{M}$ forskolin in the presence or absence of a.) LY294002 or wortmannin, b.) $1.25 \mu \mathrm{M}$ PD183452 and/or $20 \mu \mathrm{M}$ LY294002, (bottom panel- as a control islets were treated with1 $\mu \mathrm{M}$ TPA for $1 \mathrm{~h}$ in the presence or absence of $1.25 \mu \mathrm{M}$ PD183452) c.) $5 \mu \mathrm{M}$ H89 in the presence or absence of

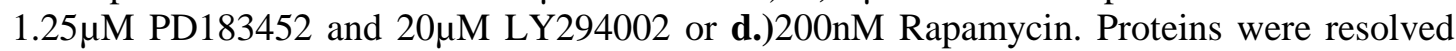
on SDS-PAGE and Western blotted using antisera against phosphorylated $(\mathrm{P}) \mathrm{rpS} 6$ on Ser(235/236) ((P)rpS6 S235/236) and Ser(240/244) ((P)rpS6 S240/244), (P)PKB Ser473, and as loading controls rpS6 or Erk2. Results shown as means \pm SE; $n=3$. ${ }^{*} P<0.05,{ }^{*} * P<0.01$. $\mathrm{P}$ value obtained using a one-way ANOVA $\mathrm{P}$ value obtained using a one-way ANOVA followed by Bonferroni adjustment. The results presented are representative of 3 independent experiments.

Figure 8: cAMP-dependent phosphorylation of rpS6 in other cell types.

Cells were pre-incubated in KRB for $1 \mathrm{~h}$. Cells were then treated for a further $1 \mathrm{~h}$ in KRB

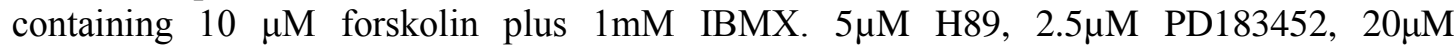
LY294002 or 200nM rapamycin were added 30min before the treatment of forskolin and IBMX. Proteins were resolved on SDS-PAGE and Western blotted using antisera specific to phosphorylated (P) rpS6 Ser(235/236) and Ser(240/244), (p)Erk1/2 and rpS6 as loading control. All results presented are representative of at least 3 independent experiments. 
ai Glucose $20 \mathrm{mM}$

- - - - 50100 nM wortmannin

$\begin{array}{lllll}C & -51020 & \text { - } & \text { - } & \text { MM LY294002 }\end{array}$

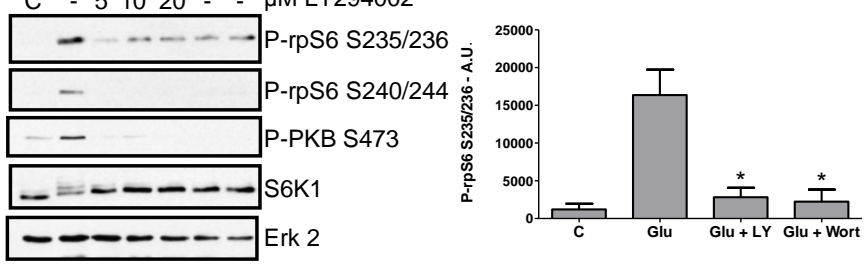

bi GLP1 bii

- - - - $50100 \mathrm{nM}$ wortmannin

C $\quad$ - 51020 - $\quad$ - $\mu$ M LY294002

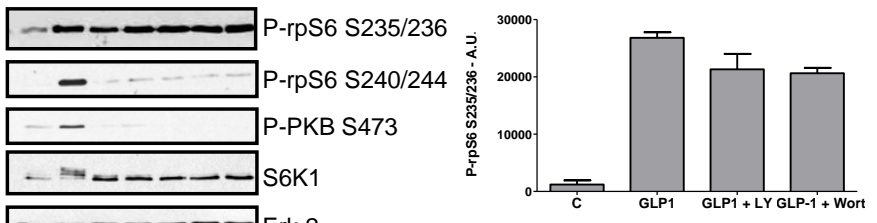

- - - - -7 Erk 2

ci Forskolin cii

- - - $50100 \mathrm{nM}$ wortmannin

C $\quad$ - 51020 - $\quad$ MM LY294002

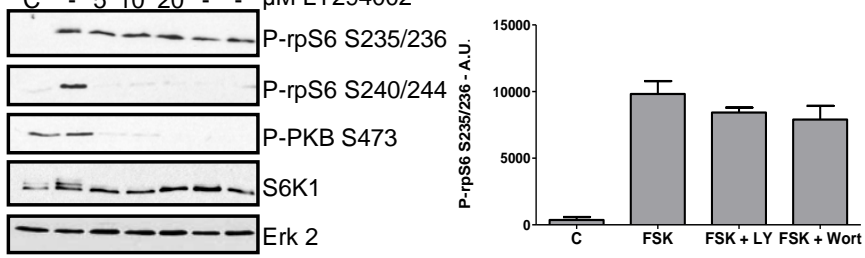

di IP:S6K1 no Ab dii

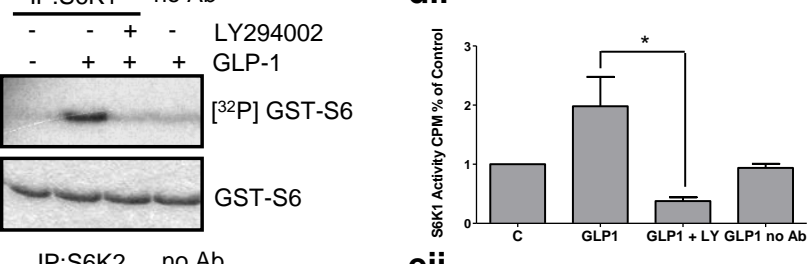

ei $\mathrm{IP}: \mathrm{S} 6 \mathrm{~K} 2$ no $\mathrm{Ab}$

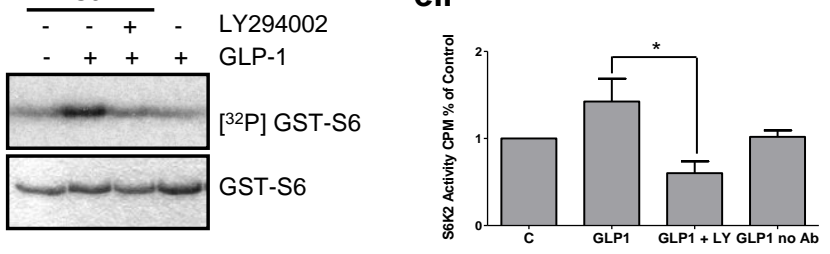

Figure 1 
ai Rapamycin

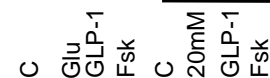

\begin{tabular}{|c|c|}
\hline-- & | P-rpS6 S235/236 \\
\hline---- & P-rpS6 S240/244 \\
\hline$-\cdots$ & P-PKB S473 \\
\hline 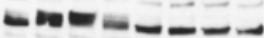 & S6K1 \\
\hline
\end{tabular}

aii

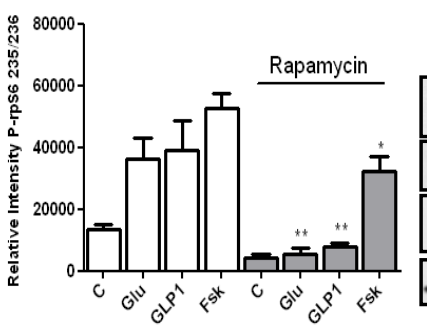

b. -+++++++++-++++++ GLP1

$++++-t_{+}+++$Rapamycin б 으은 - 응 Cantharidin $\mu \mathrm{M}$

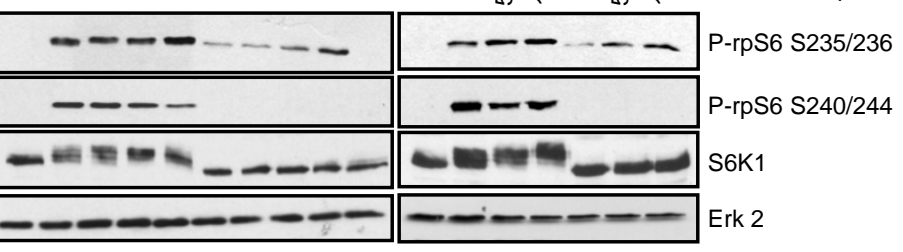

Figure 2 
a.
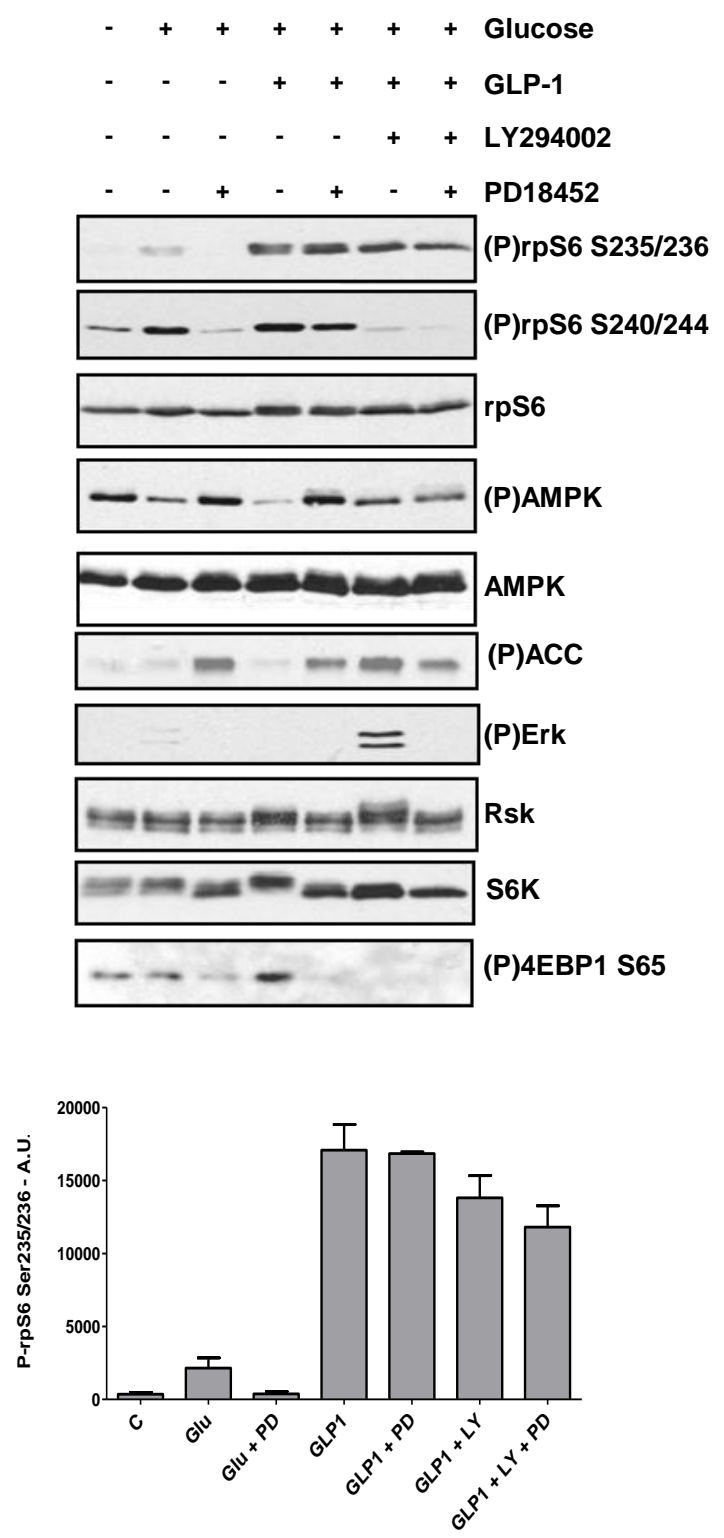

b.
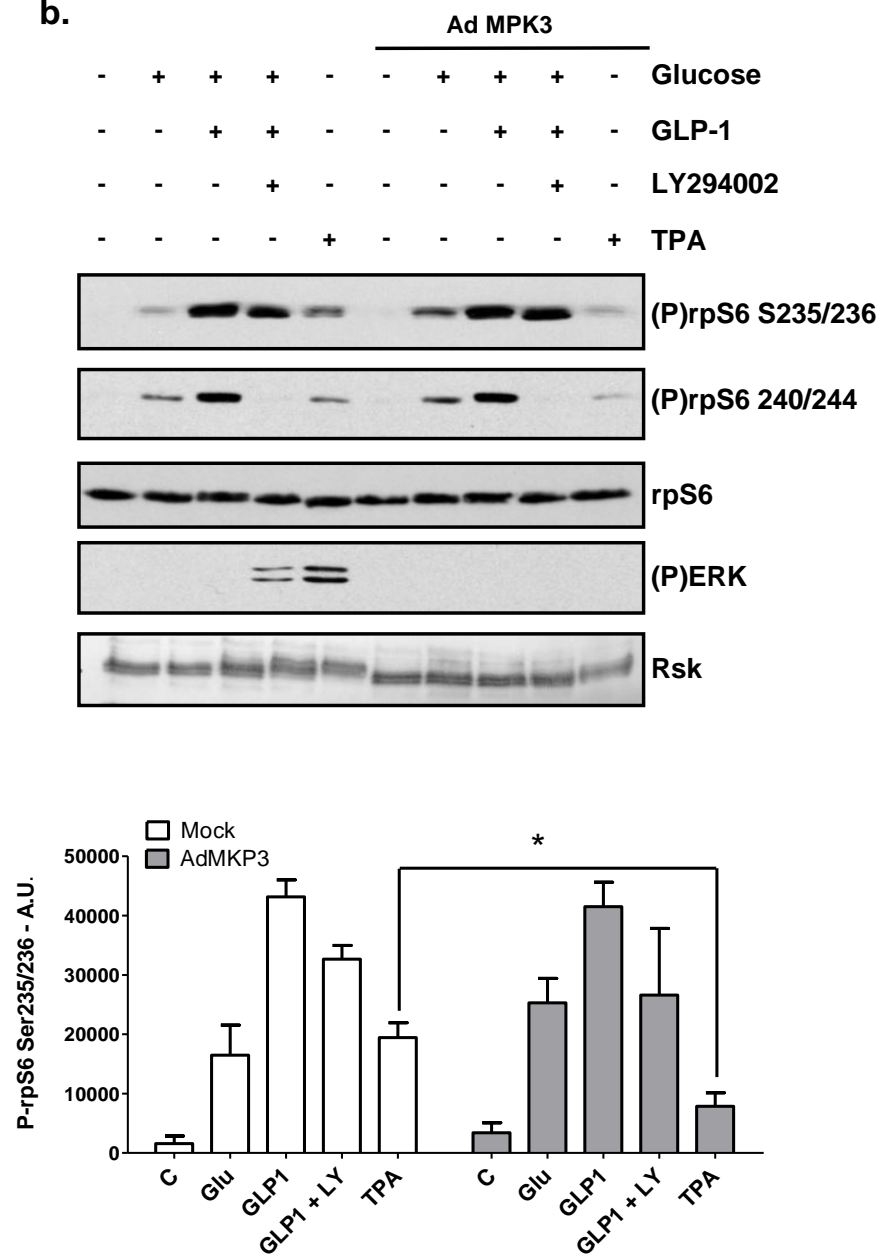

Figure 3 


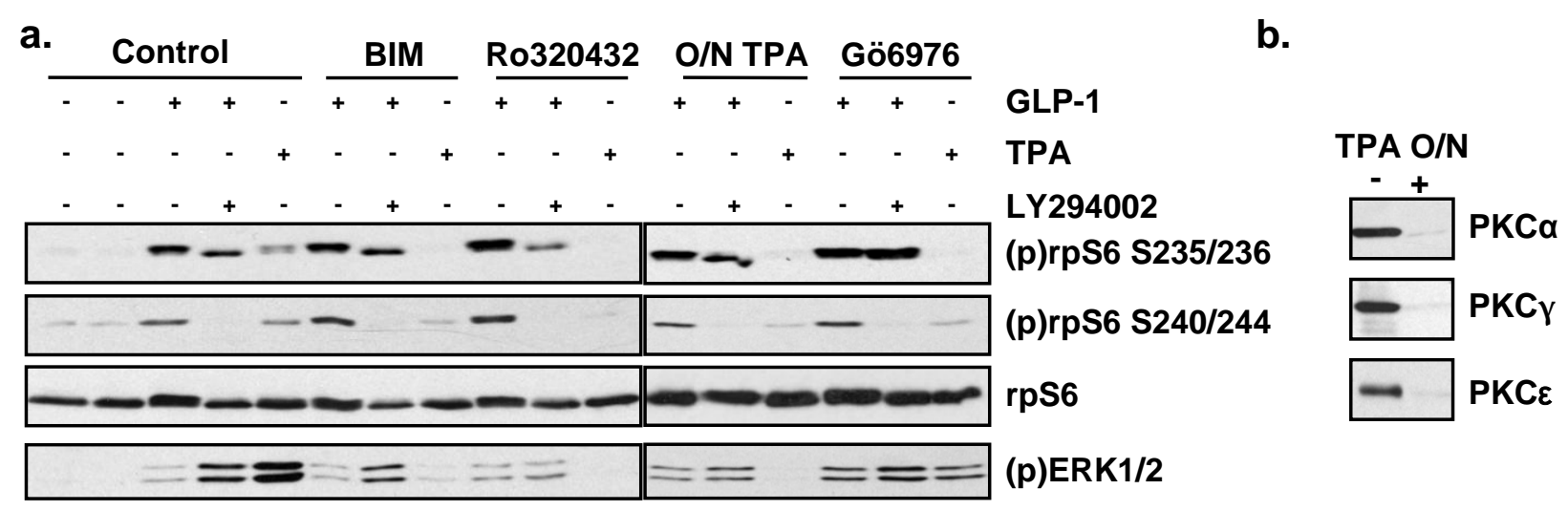

Figure 4 
ai.

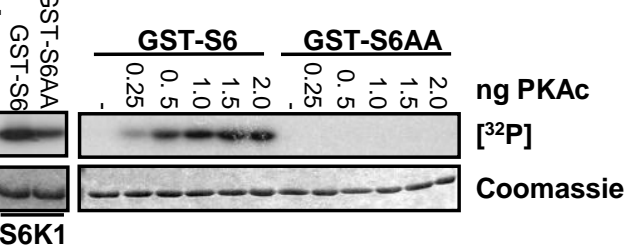

aii.

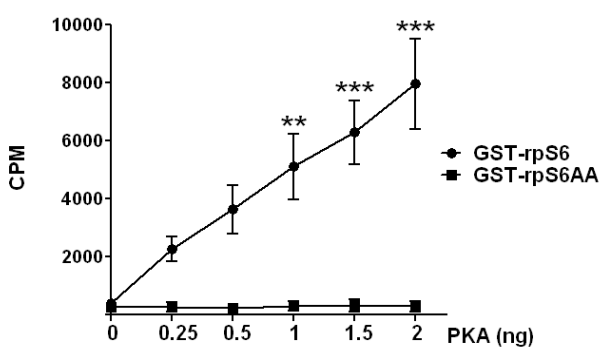

b.

\begin{tabular}{|c|c|c|c|}
\hline \multicolumn{2}{|c|}{ In vitro } & MIN6 & \\
\hline $\begin{array}{l}\mathscr{\infty} \\
0 \\
0\end{array}$ & 0 离 & 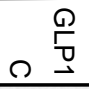 & \\
\hline 0 & - & & (P)rpS6 S235/23 \\
\hline 一 & & - & (P)rpS6 S240/244 \\
\hline- & -- & & GST-S6/rpS6 \\
\hline
\end{tabular}

Figure 5 
a.

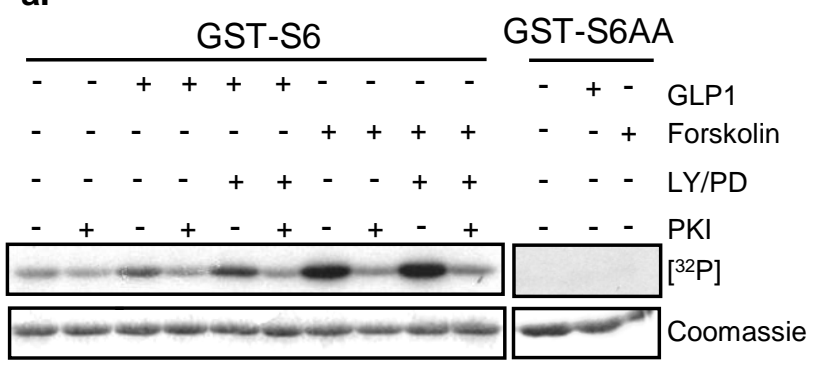

b.

\begin{tabular}{|c|c|}
\hline GLP-1 & Forskolin \\
\hline
\end{tabular}

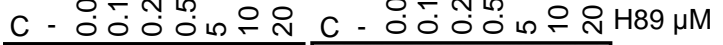

\begin{tabular}{|c|c|c|}
\hline$--\cdots$ & $--\infty-\cdots$ & (P)rpS6 S235/236 \\
\hline 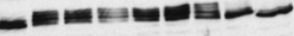 & | & S6K1 \\
\hline$-\cdots-\cdots$ & $-\cdots-\cdots$ & Erk2 \\
\hline
\end{tabular}

c.

\begin{tabular}{|c|c|c|}
\hline GLP-1 & Forskolin & \\
\hline 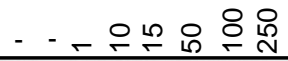 & - - 으는 융으유 신 & $\mu \mathrm{M}$ MDL12,330A \\
\hline----- & $---\cdots$ & (P)rpS6 S235/236 \\
\hline$-\infty-\infty$ & $-\infty-0$ & (P)rpS6 S240/244 \\
\hline$-\infty=-\pi=-1$ & $-\infty m a n=2-1$ & S6K1 \\
\hline & 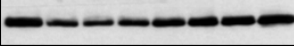 & rpS6 \\
\hline
\end{tabular}

d.

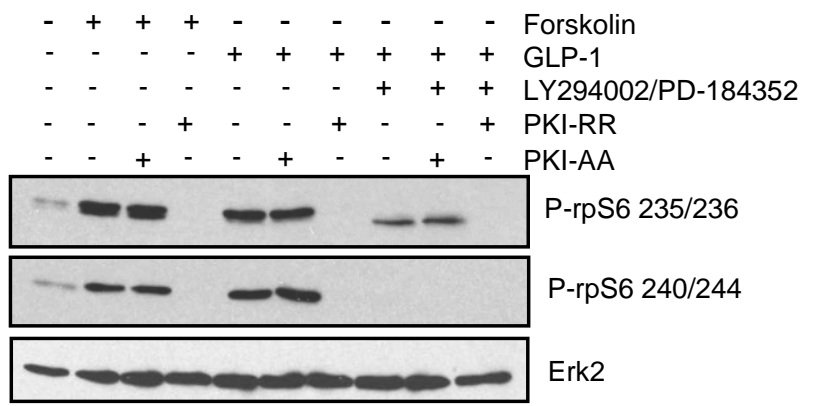

Figure 6 
a.

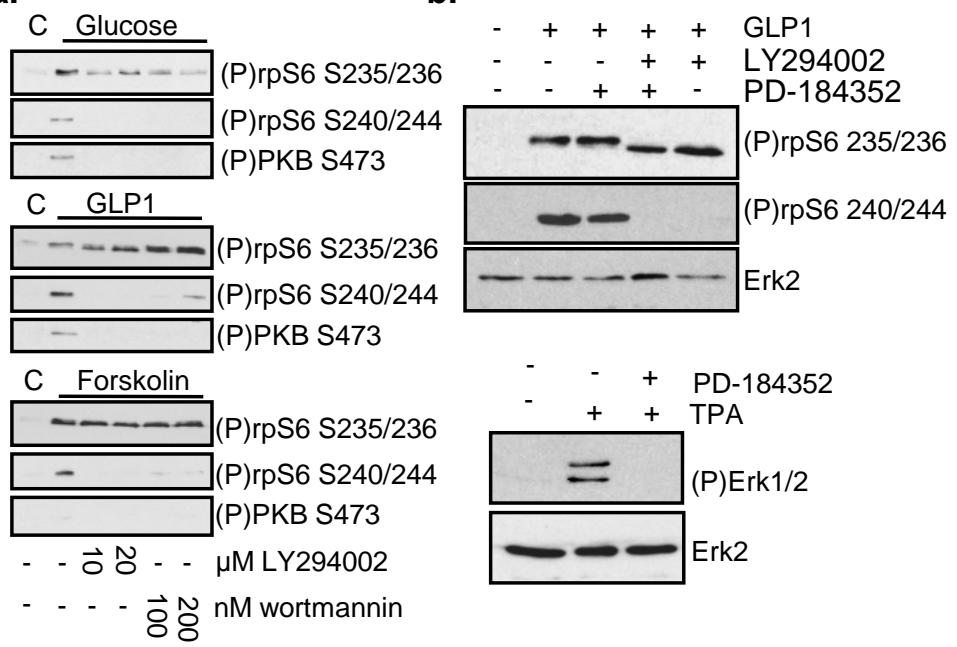

c.

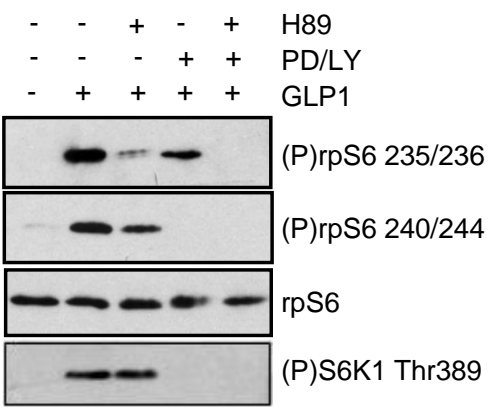

d
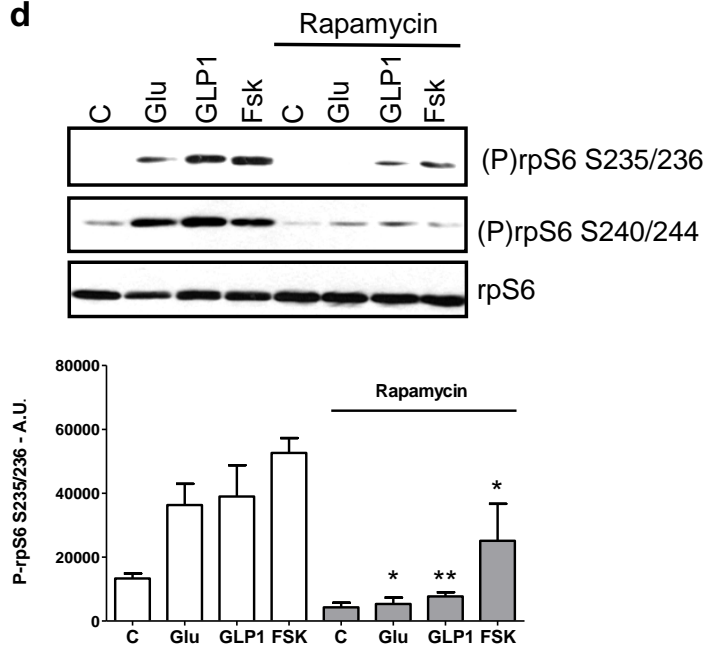

Figure 7 


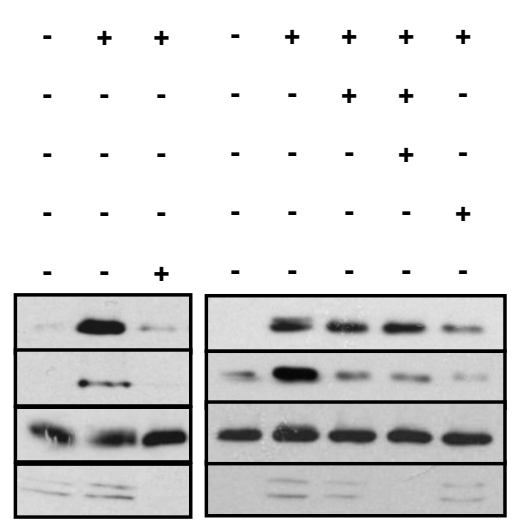

MIN6

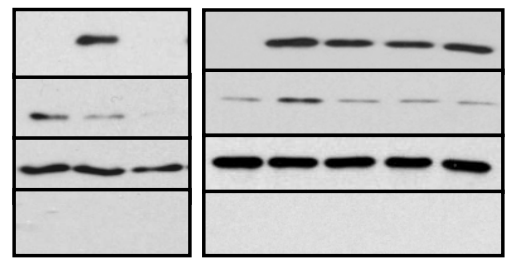

HEK293

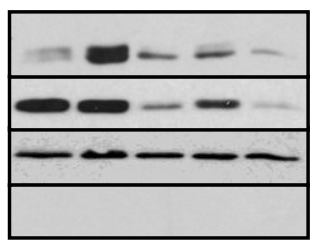

$\mathrm{CHO}$

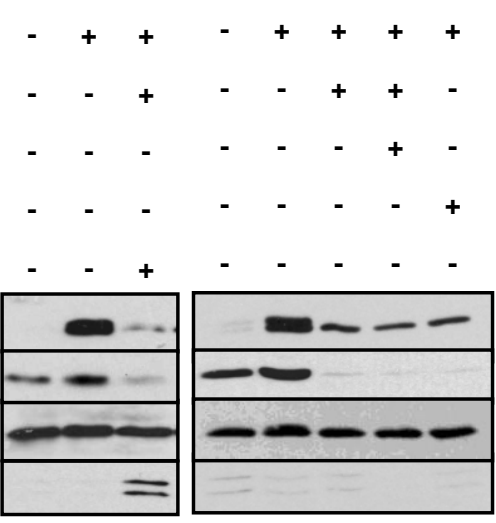

Forskolin/IBMX

LY294002

PD184352

Rapamycin

H89

(p)rpS6 235/236

(p)rpS6 240/244 rpS6

(p)ERK

PC12

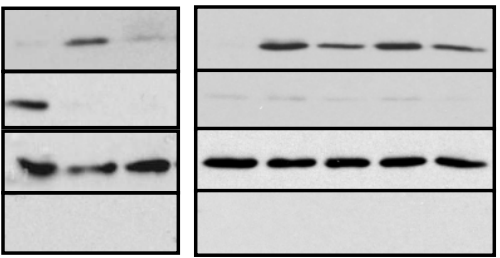

(p)rpS6 235/236

(p)rpS6 240/244 rpS6

(p)ERK

NIH3T3

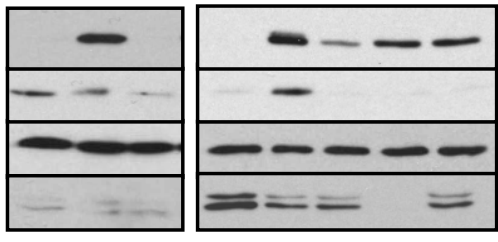

(p)rpS6 235/236

(p)rpS6 240/244 rpS6 (p)ERK

Figure 8 